\title{
New spectral functions of the near-ground albedo derived from aircraft diffraction spectrometer observations
}

\author{
C. A. Varotsos $^{1}$, I. N. Melnikova ${ }^{2}$, A. P. Cracknell ${ }^{3}$, C. Tzanis ${ }^{1}$, and A. V. Vasilyev ${ }^{4}$ \\ ${ }^{1}$ Climate Research Group, Division of Environmental Physics and Meteorology, Faculty of Physics, University of Athens, \\ University Campus Bldg. Phys. V, Athens 15784, Greece \\ ${ }^{2}$ Laboratory for Atmospheric Physics, Research Center for Interdisciplinary Environmental Cooperation (INENCO RAS), \\ Russian Academy of Sciences, St. Petersburg, Russia \\ ${ }^{3}$ Division of Electronic Engineering and Physics, University of Dundee, Dundee DD1 4HN, Scotland, UK \\ ${ }^{4}$ Institute of Physics, St. Petersburg State University, Ulyanovskaya 1, 198504 St. Petersburg, Russia \\ Correspondence to: C. A. Varotsos (covar@phys.uoa.gr)
}

Received: 1 April 2013 - Published in Atmos. Chem. Phys. Discuss.: 15 June 2013

Revised: 28 September 2013 - Accepted: 2 June 2014 - Published: 9 July 2014

\begin{abstract}
The airborne spectral observations of the upward and downward irradiances are revisited to investigate the dependence of the near-ground albedo as a function of wavelength in the entire solar spectrum for different surfaces (sand, water, snow) and under different conditions (clear or cloudy sky). The radiative upward and downward fluxes were determined by a diffraction spectrometer flown on a research aircraft that was performing multiple flight paths near the ground. The results obtained show that the near-ground albedo does not generally increase with increasing wavelengths for all kinds of surfaces as is widely believed today. Particularly, in the case of water surfaces it was found that the albedo in the ultraviolet region is more or less independent of the wavelength on a long-term basis. Interestingly, in the visible and near-infrared spectra the water albedo obeys an almost constant power-law relationship with wavelength. In the case of sand surfaces it was found that the sand albedo is a quadratic function of wavelength, which becomes more accurate if the ultraviolet wavelengths are neglected. Finally, it was found that the spectral dependence of snow albedo behaves similarly to that of water, i.e. both decrease from the ultraviolet to the near-infrared wavelengths by $20-50 \%$, despite the fact that their values differ by one order of magnitude (water albedo being lower). In addition, the snow albedo vs. ultraviolet wavelength is almost constant, while in the visible near-infrared spectrum the best simulation is achieved by a second-order polynomial, as in the case of sand, but with opposite slopes.
\end{abstract}

\section{Introduction}

Studies of climate change are of enormous scientific and human importance, and a key component of these studies is climate modelling. Any climate model has to take into account the energy balance at and near the Earth's surface and this, in turn, involves knowing the absorption and reflection factors of the materials of the Earth's surface. When solar radiation moves from an atmospheric layer into another, both reflection and refraction may occur that are fully described by the Fresnel equations. As far as the refraction is concerned, the refractive index is interrelated with a dielectric constant which depends on temperature and frequency (Varotsos and Miliotis, 1974; Varotsos, 1980; Kostopoulos et al., 1975). Regarding the reflection the term albedo is often used. The albedo $(A)$ is the dimensionless fraction of the reflected electromagnetic radiation from a surface to the radiation incident upon it, ranging from zero (for no reflection of the radiation by a perfectly absorbing black surface) to 1 (for complete reflection by a white totally reflecting surface).

The albedo depends on the wavelength of the radiation and the optical features of the reflecting surface, and as a result it is involved in the Earth's radiative budget, being thus a crucial climate forming factor of our planet. In this context, the average surface temperature of our planet is mainly controlled by its albedo and the atmospheric greenhouse effect (Cracknell and Varotsos, 1994, 1995, 2007a, b, c; Varotsos, 2002, 2005a, b; Feretis et al., 2002; Efstathiou et al., 2003; 
Tzanis et al., 2008; Varotsos et al., 2008, 2012a, b; Chattopadhyay and Chattopadhyay, 2010; Efstathiou and Varotsos, 2010, 2013; Xue et al., 2011; de la Fuente et al., 2011). For example, the average Earth surface temperature would be $-40{ }^{\circ} \mathrm{C}$ if it were frozen entirely and $27^{\circ} \mathrm{C}$ if all the ice on its surface were to melt. In addition, the albedo reduction, due to snow melting, causes more sunlight absorption, thus increasing the surface temperature (Pegau and Paulson, 2001).

There are two sources of surface albedo observations, notably the Baseline Surface Radiation Network (McArthur, 2005), providing continuous, long-term measurements of surface radiation fluxes using tower-mounted pyranometers, and the remotely sensed ones conducted via aircraft and satellite-flown instrumentation.

The albedo of the Earth's surface varies widely from place to place and also, to some extent, as a function of time too. In constructing a detailed climate model one needs to have available real data on a rather fine grid rather than just assuming an average value over a wide area, and remote sensing provides the only realistic way to obtain and update such data. The flux tower data are only available from a rather small number of locations while there are huge areas from which no data are available. They do, however, provide direct measurements of the quantity required, the albedo. The remotely sensed systems do provide data over the required global grid that is necessary for climate modelling, but the data must be interpreted by employing radiative transfer models that provide the variables under consideration from the raw observational data. In the case of satellite observations the majority of the algorithms used rely on multiple cloud-free directional satellite observations to first build a bidirectional reflectance distribution function (BRDF) model of the surface. This model is angularly integrated to produce the reflected shortwave flux. However, it is not always feasible to collect the needed observations in a single satellite pass, and therefore complementary data from multiple orbits must be used, reconciling then the varying atmospheric and irradiance effects. For albedo studies a combination of geostationary and polar orbiting satellites is preferable, validating the satellite products with those of the ground-based network.

In remote sensing science the surface albedo precision is of crucial importance. For instance, surface albedo uncertainties result in large retrieval errors of the aerosol optical depth, particularly close to the critical surface albedo (defined as the surface albedo, where the reflectance at the top-of-atmosphere does not depend on aerosol optical depth) (Seidel and Popp, 2012; Teillet et al., 1994). In addition, the Moderate Resolution Imaging Spectroradiometer (MODIS) instruments on board the Terra and Aqua satellites reveal that the Earth's albedo varies widely, depending on the geological and environmental features, getting an average value (or planetary albedo) of $0.3-0.35$, mainly because of the cloudiness (Cescatti et al., 2012; Lyapustin et al., 2009). As an example, the maximum Earth terrestrial albedo is found in the tropics, while the minimum is observed in the subtropical regions of both hemispheres. Other satellite instruments providing albedo products are the Multi-angle Imaging SpectroRadiometer (MISR), Clouds and the Earth's Radiant Energy System (CERES), Polarization and Directionality of the Earth's Reflectances (POLDER), Medium Resolution Imaging Spectrometer (MERIS), Meteosat, and Meteosat Second Generation (MSG), the European geostationary meteorological satellite system.

According to the experimental observations in the visible spectrum the typical value of albedo for snow is 0.85 , for water 0.02 at small angles of incident light (Haltrin et al., 2001) and for clouds ranging from 0 to 0.8 depending on the type of cloud. It is important to remember that snow albedo is most sensitive to impurities. Very recently, Hadley and Kirchstetter (2012) performed laboratory measurements in an effort to quantify the reduction in snow albedo as a function of its contamination with black carbon, which is an important parameter in the available atmospheric solar radiative transfer and climate models (Alexandris et al., 1999; Brandt et al., 2011; Doherty et al., 2010; Flanner et al., 2007; Gallet et al., 2009; Katsambas et al., 1997; Kondratyev et al., 1995; Kondratyev and Varotsos, 1995a, b, 1996a, b; Monks et al., 2004; Varotsos et al., 1995). According to Hadley and Kirchstetter (2012), $200 \mathrm{ppb}$ of black carbon is required to decrease the snow albedo by $5 \%$. For comparison reasons only 10 $20 \mathrm{ppb}$ of black carbon (the typical level for many natural environments) decreases snow albedo by $1 \%$, an amount that is enough to contribute to global warming, also accelerating ice melting (Flanner et al., 2007; Hansen and Nazarenko, 2004).

In summary, the satellite-borne remote sensing techniques employ many necessary steps for the retrieval of surface albedo, each with its own set of assumptions and uncertainties. For instance, some techniques have ignored BRDF and assumed a Lambertian surface (i.e. reflecting equally in all directions). Others have applied atmospheric models using climatological atmospheric profiles rather than field measurements. These simplifications, however, can lead to larger errors, while the accuracies of \pm 0.02 to \pm 0.05 are necessary for general circulation models (GCMs).

The present paper presents an investigation of the in-field spectral albedo of the Earth's surface with high-resolution observations from the ultraviolet (UV) to the near-infrared (NIR) that were acquired by multiple aircraft flights over water, sand and snow surfaces. The findings will contribute to the solution of the remote sensing problems stemming from the heterogeneity of albedo and reflectance anisotropy (Schaepman-Strub et al., 2006; Román et al., 2011). In addition, these findings will improve the accuracy and precision of the assessment of the Earth's "radiation budget", which is calculated as the absorbed shortwave radiation minus the outgoing longwave radiation, where one critical parameter is the surface albedo. However, small errors in albedo can translate into large errors in energy estimates. This makes it important 
Table 1. Dates, time, solar elevation and locations of the flights implemented over sand, water and snow.

\begin{tabular}{llllllll}
\hline $\begin{array}{l}\text { Dates of flights } \\
\text { over sand }\end{array}$ & Lat. $\left(^{\circ}\right)$ & Long. $\left(^{\circ}\right)$ & $\begin{array}{l}\text { Moscow time } \\
\text { (astr/mic) }\end{array}$ & Greenwich time & Elevation $h$ & Zenith angle $\theta$ & cos $\theta$ \\
\hline 9 Oct 1983 & 39 & 60 & $09: 47$ & $07: 47$ & $28^{\circ} 34^{\prime} 40^{\prime \prime}$ & $61.5^{\circ}$ & 0.477 \\
10 Oct 1983 & 39 & 60 & $09: 47$ & $07: 47$ & $28^{\circ} 19^{\prime} 24^{\prime \prime}$ & $61.7^{\circ}$ & 0.474 \\
11 Oct 1983 & 39 & 60 & $10: 06$ & $08: 06$ & $30^{\circ} 54^{\prime} 36^{\prime \prime}$ & $59^{\circ}$ & 0.515 \\
12 Oct 1983 & 39 & 60 & $09: 05$ & $07: 05$ & $21^{\circ} 00^{\prime} 19^{\prime \prime}$ & $69^{\circ}$ & 0.358 \\
13 Oct 1983 & 39 & 60 & $10: 47$ & $08: 47$ & $39^{\circ} 35^{\prime}$ & $52^{\circ} 25^{\prime}$ & 0.610 \\
14 Oct 1983 & 39 & 60 & $10: 12$ & $08: 12$ & $41^{\circ} 52^{\prime}$ & $50^{\circ} 18^{\prime}$ & 0.639 \\
16 Oct 1983 & 39 & 60 & $10: 03$ & $08: 03$ & $33^{\circ} 54^{\prime}$ & $51^{\circ}$ & 0.629 \\
19 Oct 1984 & $38: 35$ & $63: 20$ & $09: 47$ & $07: 47$ & $25^{\circ} 48^{\prime} 30^{\prime \prime}$ & $64.2^{\circ}$ & 0.435 \\
23 Oct 1984 & $38: 35$ & $63: 20$ & $10: 05$ & $08: 05$ & $38^{\circ} 18^{\prime}$ & $53^{\circ} 42^{\prime}$ & 0.592 \\
24 Oct 1984 & $38: 35$ & $63: 20$ & $08: 09$ & $06: 09$ & $18^{\circ} 14^{\prime} 40^{\prime \prime}$ & $71.75^{\circ}$ & 0.313 \\
26 Oct 1984 & $38: 35$ & $63: 20$ & $09: 14$ & $07: 14$ & $39^{\circ} 17^{\prime} 33^{\prime \prime}$ & 50.8 & 0.632 \\
\hline 13 May 1984 & $60: 35$ & $31: 31$ & $12: 55$ & $10: 55$ & $48^{\circ} 26^{\prime}$ & $51^{\circ} 34^{\prime}$ & 0.622 \\
14 May 1984 & $60: 38$ & $31: 36$ & $12: 35$ & $10: 35$ & $39^{\circ} 53^{\prime}$ & $50.2^{\circ}$ & 0.640 \\
15 May 1984 & $60: 32$ & $31: 33$ & $12: 44$ & $10: 44$ & $47^{\circ} 37^{\prime}$ & $52^{\circ} 23^{\prime}$ & 0.611 \\
16 May 1984 & $60: 33$ & $31: 35$ & $12: 46$ & $10: 46$ & $47^{\circ} 22^{\prime} 25^{\prime \prime}$ & $42.7^{\circ}$ & 0.735 \\
17 May 1984 & $60: 39$ & $31: 32$ & $12: 56$ & $10: 56$ & $48^{\circ} 31^{\prime}$ & $51^{\circ} 29^{\prime}$ & 0.623 \\
18 May 1984 & $60: 35$ & $31: 33$ & $12: 19$ & $10: 19$ & $48^{\circ} 41^{\prime}$ & $41.4^{\circ}$ & 0.750 \\
\hline 14 Apr 1985 & $61: 30$ & $31: 30$ & $10: 44$ & $8: 44$ & $32^{\circ} 11^{\prime}$ & $57^{\circ} 49^{\prime}$ & 0.542 \\
28 Apr 1985 & $60: 49$ & $31: 52$ & $13: 51$ & $11: 51$ & $47^{\circ} 01^{\prime}$ & $52^{\circ} 59^{\prime}$ & 0.602 \\
26 Mar 1984 & $61: 53$ & $31: 35$ & $12: 57$ & $10: 57$ & $31^{\circ} 33^{\prime}$ & $59^{\circ} 27^{\prime}$ & 0.508 \\
\hline
\end{tabular}

to actually measure the albedo of e.g. snow-covered areas rather than apply single-value climatological averages over broad regions and time periods, given that snow albedo is highly variable, ranging from as high as 0.9 for freshly fallen snow, to about 0.4 for melting snow, and as low as 0.2 for dirty snow.

\section{Data and instrumentation}

\subsection{Experimental campaign and equipment}

The observations were obtained with a well-calibrated diffraction spectrometer flown on an experimental aircraft. This spectrometer includes three components: a light flux disk shutter with a modulator, a monochromator with a diffraction lattice and a receiving-recording unit. In particular, the monochromator (operating in the spectral region 250-1000 nm) is of Ebert-Fastie type and comprises an entrance and three exit slits, two concave spherical mirrors (with a focal length of $300 \mathrm{~mm}$ ) and replica grating with 600 lines $\mathrm{mm}^{-1}$. Three photomultipliers were employed as detectors in the wavelength $(\lambda)$ ranges: $\lambda \leq 400 \mathrm{~nm}$, $350 \mathrm{~nm} \leq \lambda \leq 700 \mathrm{~nm}$ and $650 \mathrm{~nm} \leq \lambda \leq 1000 \mathrm{~nm}$. The spectral resolution of the spectrometer was $2 \mathrm{~nm}$ and the recording time for one spectrogram was around $7 \mathrm{~s}$. An automatically rotating periscope alternatively detected the radiative downward and upward fluxes within $3 \mathrm{~s}$ (the time for its up and down motion). More structural details for this spectrom- eter and its accuracy are given by Melnikova and Mikhaylov (1994).

Complementary information on the instrumentation is also given by Melnikova and Vasilyev (2004) and in Melnikova (2005). It should be clarified that the aircraft performed near-ground flight paths $(\approx 0.5 \mathrm{~km})$ and thus the atmospheric masking to the calculated albedo was negligible (Webb et al., 2000). To avoid however any bias of the observations from atmospheric scattering and absorption between the surface and the flight level, the data were corrected by retrieving the areal spectral surface albedo (Wendisch et al., 2004).

Table 1 depicts the primary details of the conducted experimental campaigns, which will be discussed in the next section in detail. Apart from these observations, earlier and later aircraft campaigns will also be presented in order to elaborate the principal findings of this paper. For instance, the NASA airborne data will additionally be presented, which have been obtained below a cloud layer by aircraft flights at an altitude around $350 \mathrm{~m}$ at South Africa $\left(20.0-21.7^{\circ} \mathrm{S}, 13.0-13.7^{\circ} \mathrm{E}\right)$ (Gatebe et al. 2003; Genya et al., 2011). These observations were made in eight spectral channels, 340, 381, 472, 682, 870, 1.035, 1.219, and $1.273 \mathrm{~nm}$, with the Cloud Absorption Radiometer (CAR) (King, 1987; King et al., 1990, 1996; Gatebe et al. 2003, 2005).

In the following section the accuracy and precision of the methods employed and the observations collected will be presented in detail. 
Table 2. Deviation of the zeroth harmonic $\rho^{0}(0.67,0.67)$ of the reflection function from unity.

\begin{tabular}{lllllll}
\hline$g$ & 0.3 & 0.5 & 0.75 & 0.8 & 0.85 & 0.9 \\
\hline$\left|1-\rho^{0}(0.67,0.67)\right|$ & 0.0037 & 0.024 & 0.021 & 0.0059 & 0.013 & 0.0046 \\
\hline
\end{tabular}

Table 3. Albedo $\left(A_{\mathrm{S}}\right)$ of the Atlantic Ocean surface, derived from airborne observations conducted by the CAR instrument at various wavelengths $(\lambda)$ (MSD: mean square deviation).

\begin{tabular}{lllllllll}
\hline$\lambda, \mathrm{nm}$ & 340 & 381 & 472 & 682 & 870 & 1035 & 1219 & 1273 \\
\hline$A_{S}$ & 0.0674 & 0.0706 & 0.0511 & 0.0464 & 0.0437 & 0.0422 & 0.0409 & 0.0441 \\
$\mathrm{MSD}$ & 0.0036 & 0.015 & 0.0012 & 0.0012 & 0.0012 & 0.0012 & 0.0010 & 0.0012 \\
\hline
\end{tabular}

\subsection{Accuracy and precision of the methods and observations}

Regarding the degree of closeness of the calculated albedo values to the actual (true) albedo values (accuracy), the following must be taken into account. In the case of using the solar irradiance observations, the albedo values are conventionally inferred by dividing the upwelling irradiance by the downwelling one at the bottom of the atmosphere (at the lowest observational level, that is the lowest flight level of about $0.2-0.5 \mathrm{~km})$. In the case of using radiance, however, the situation is more complicated. For instance, in overcast sky conditions the convenient approach proposed by Melnikova et al. (2000) was utilised. In particular, the value of the cosine of the zenith viewing angle $\mu=0.67$ (which corresponds to $48^{\circ}$ ) leads to the case when the zeroth harmonic of the reflection function $\rho^{0}$ is close to unity. Thus, the reflected radiance measured at viewing angles close to $48^{\circ}$ is equal to the reflected irradiance (the same is also true for transmitted radiation). Both irradiance and radiance measured at solar zenith angle $48^{\circ}$ approximately coincide with the spherical albedo of the cloud layer. For the observations presented here, the deviation of the zeroth harmonic of the reflected function from unity $\left|1-\rho^{0}\left(\mu, \mu_{0}\right)\right|$ is presented in Table 2, when the phase function asymmetry parameter $g$ varies in the interval $(0.3,0.9)$ and $\mu=\mu_{0}=0.67$. Normally the parameter $g$ varies between -1 and 1 , and for $g>0$, forward scattering is dominant, while for $g<0$, backscattering predominates. From Table 2 it is evident that the deviation from unity is about $10 \%$.

It should be stressed that according to King (1987) the reflection function that is calculated for the Mie phase function (fair weather cumulus clouds) differs from unity by $2-5 \%$ at zenith angles in the range $47-50^{\circ}$. Hence, for the observations that were conducted at these zenith angles and are presented here, the reflection function is close to unity.

It should be noted that the diffused radiation field is very important at the viewing or solar directions around $48^{\circ}$. In this regard, Boucher (1998) suggested that if the solar incident angle is about $45-50^{\circ}\left(0.643<\mu_{0}<0.707\right)$, the impact of different phase functions on the radiative forcing is almost the same. Concerning the influence of scattering effects on our observations the suggestion made by Kokhanovsky (1998) was taken into account, according to which the particle size distribution has a slight influence on cloud phase function at scattering angles about $90^{\circ}$ (that approximately corresponds to cosines of zenith angle $\mu_{0}=\mu=0.67$ ).

The application of the above-mentioned approach to the ground albedo estimation from diffuse radiance observation provides the result presented in Table 3 . The relative mean square deviation obtained from averaging over 10 scan points shows the small error in the degree of reproducibility or repeatability of the observations (precision).

\section{Discussion and results}

\subsection{Spectral water albedo}

\subsubsection{Water albedo vs. wavelength in the entire solar spectrum}

Starting from the case of the water surface Fig. 1 is presented, which illustrates the variability of the near-ground albedo values derived from the radiative upward and downward fluxes measured by the research aircraft flying very close $(0.4-0.5 \mathrm{~km})$ to the water surface of Lake Ladoga between 13 May and 18 May 1984 under clear sky conditions (see Table 1).

The principal result drawn from Fig. 1 is that the water albedo decays with wavelength throughout the solar spectrum. It is worth noting that the seven spectrograms recorded over Ladoga between 13 and 18 May 1984 give almost coincident decay curves with an average fit line simulated by the power-law equation $A=2541.1 \lambda^{-1.76}$ with $R^{2}=0.97$. As far as the UV region is concerned, the water albedo shows a remarkable maximum around $335 \mathrm{~nm}$, which will be discussed in the next subsection. 
Table 4. Dates and fit equations along with the errors of the coefficients for water albedo shown in Fig. 3. All given $a, b$ values are statistically significant at the $95 \%$ confidence interval.

\begin{tabular}{lccc}
\hline Dates & Power-law fit equation $\left(y=a x^{\mathrm{b}}\right)$ & Error for $a$ & Error for $b$ \\
\hline 13 May 1984 & $y=2783.9 x^{-1.78}$ & 327.2 & 0.02 \\
14 May 1984 & $y=2783.8 x^{-1.78}$ & 327.2 & 0.02 \\
15 May 1984 & $y=2776.3 x^{-1.78}$ & 326.7 & 0.02 \\
16 May 1984 & $y=2777.7 x^{-1.78}$ & 327.1 & 0.02 \\
17 May 1984 & $y=2780.5 x^{-1.78}$ & 327.6 & 0.02 \\
18 May 1984 & $y=2748.9 x^{-1.77}$ & 322.1 & 0.02 \\
\hline
\end{tabular}

Table 5. Fit equations along with the errors of the coefficients for sand albedo and for the three dates shown in Fig. 4 . All given $a, b$, and $c$ values are statistically significant at the $95 \%$ confidence interval.

\begin{tabular}{lllll}
\hline Dates & $\begin{array}{l}\text { Second-order polynomial } \\
\text { fit equation } \\
\left(y=a x^{2}+b x+c\right)\end{array}$ & Error for $a$ & Error for $b$ & Error for $c$ \\
\hline 12 Oct 1983 & $y=-1 \times 10^{-6} x^{2}+0.0025 x-0.6144$ & $3.1 \times 10^{-8}$ & $4.1 \times 10^{-5}$ & 0.0123 \\
13 Oct 1983 & $y=-9 \times 10^{-7} x^{2}+0.0018 x-0.4238$ & $3.3 \times 10^{-8}$ & $4.2 \times 10^{-5}$ & 0.0125 \\
23 Oct 1984 & $y=-1 \times 10^{-6} x^{2}+0.002 x-0.4347$ & $3.2 \times 10^{-8}$ & $4.1 \times 10^{-5}$ & 0.0121 \\
\hline
\end{tabular}

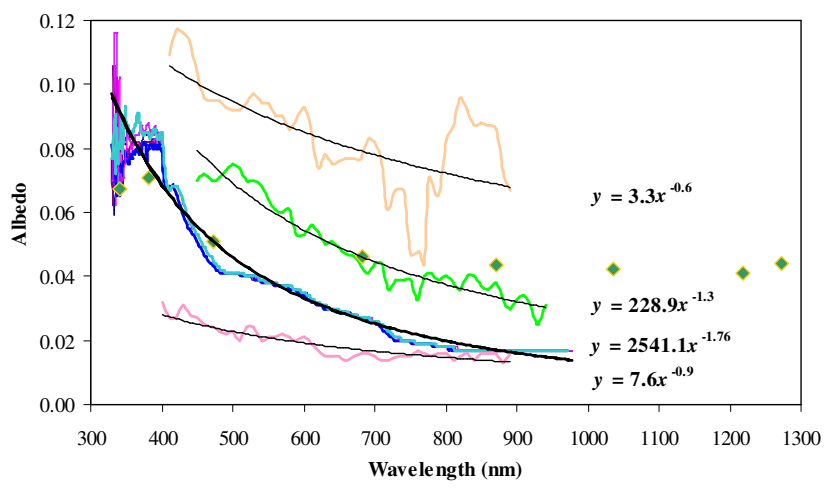

Figure 1. Spectral dependence of the water albedo throughout the spectrum from the UV to the near-infrared. Green line: Black Sea. (Pink, cyan, blue, deep pink) lines: Lake Ladoga. Burlywood line: Atlantic Ocean (12 July 1974). Dark green squares: NASA values (Atlantic Ocean, 13 September 2000). Rose line: Sea of Azov (15 October 1972).

\subsubsection{Water albedo vs. wavelength in the UV region}

As mentioned in Sect. 3.1.1, the power-law fit seems to offer an accurate simulation of the variation of the water albedo vs. wavelength from the UV spectrum to the NIR region (see Fig. 1). However, a careful inspection of Fig. 1 shows that the spectral water albedo in UV does not fit well to the powerlaw approximation, despite the fact that the entire spectral profile of water albedo is accurately simulated by the powerlaw fit. In fact, it is obvious from Fig. 2, which presents the albedo profiles derived from multiple spectrograms that were recorded on five consecutive days. The remarkable feature in
Fig. 2 is that on a long-term scale the spectral water albedo in the UV region is almost constant. This conclusion suggests that the simulation of the spectral dependence of the water albedo in the UV and visible NIR must be investigated separately. It will be done in the next subsection.

Before that, it should be noted that the local maxima observed in the interval $330-340 \mathrm{~nm}$ may be attributed to the fact that Rayleigh scattering (and thus reflectivity) increases towards smaller wavelengths.

\subsubsection{Water albedo vs. wavelength in the visible IR region}

The above-mentioned finding about the independence of the water albedo from the wavelength in the UV region dictates the necessity for re-examining the spectral water albedo vs. wavelength in the visible and NIR regions, first eliminating that of the UV.

The results obtained are depicted in Fig. 3 (see also Table 4 for errors), where the most remarkable feature is that the water spectral albedo in the visible and the NIR regions obey the same power-law relationship. A comparison between Figs. 1 and 3 shows that, investigating the water albedo in the entire spectrum (from UV to NIR), the simulating power-law relationship varies from profile to profile, whilst it remains almost the same if this investigation is made from the visible to the NIR region (neglecting UV). In addition, Fig. 1 provides a false impression of the spectral variability of water albedo in the UV region (i.e. power-law dependence), since Fig. 2 dictates an independence of the water albedo over a long range of UV wavelengths. 


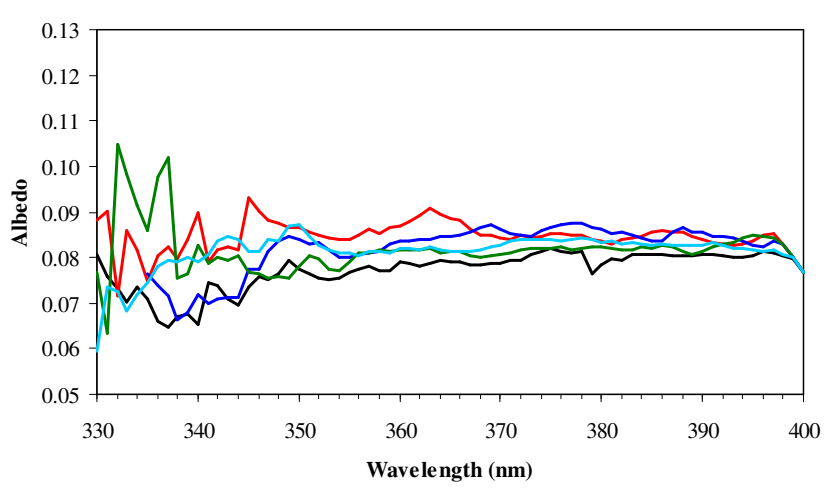

Figure 2. Spectral variability of albedo for water surface in the UV region only measured on 13 May 1984 (black line), 14 May 1984 (red line), 15 May 1984 (blue line), 16 May 1984 (green line) and 17 May 1984 (cyan line).

\subsection{Spectral sand albedo}

\subsubsection{Sand albedo vs. wavelength in the entire solar spectrum}

Now the sand albedo as a function of wavelength is studied by utilising the airborne observations conducted by the diffraction spectrometer flown on the research aircraft during its multiple flights above sand surfaces (see Table 1).

Figure 4 (see also Table 5 for errors) depicts the spectral dependence of the sand albedo, as deduced from the aircraft near-ground $(\approx 0.5 \mathrm{~km})$ observations of the radiative upward and downward fluxes made over the Kara-Kum Desert on 12 October 1983, 13 October 1983 and 23 October 1984. Inspection of Fig. 4 shows that the multiple albedo profiles derived from the spectrograms collected over sand follow a quadratic polynomial, with maximum sand albedo at the NIR spectral range.

A comparison between Figs. 1 and 4 reveals that the spectral dependence of water and sand albedo is opposite. Although both start from a typical albedo value of 0.08 in the UV spectral region, the sand albedo increases by around a tenfold value in the NIR region, whilst the water albedo decreases by $20-50 \%$.

\subsubsection{Sand albedo vs. wavelength in the UV region}

It would be interesting to investigate now the variation in the sand albedo as a function of wavelength in the UV region. Figure 5 illustrates the variation of the sand albedo vs. wavelength in the UV spectrum, as deduced from the airborne observations of the radiative upward and downward fluxes that were measured on eleven experimental days with multiple aircraft flights.

A remarkable minimum of the sand albedo is clearly seen in Fig. 5 just after a very noisy albedo region varying between 0.05 and 0.18 . It is interesting to recall at this point the water albedo maximum observed at the same wavelength, i.e. $365 \mathrm{~nm}$ (Fig. 1). Low values of sand albedo and the transparent absorption band at $950 \mathrm{~nm}$ shown in Fig. 4 might thus be explained by increased moisture of sand.

\subsubsection{Sand albedo vs. wavelength in the visible IR region}

In the following, the sand albedo variation as a function of wavelength in the visible NIR spectral region is investigated. Several experimental albedo profiles for sand are shown in Fig. 6 (see also Table 6 for errors). For these profiles the best simulation is achieved with a second-order polynomial fit, as in Fig. 4. A comparison between Figs. 6 and 4 shows that neglecting the fragment of the albedo profile that corresponds to the UV spectrum renders the simulation of the secondorder polynomial more accurate (much higher $R^{2}$ ).

\subsection{Spectral snow albedo}

\subsubsection{Snow albedo vs. wavelength in the entire solar spectrum}

The case of snow is of special interest. This is due to the fact that the snow state is of crucial importance for the profile of its spectral albedo dependence. In this regard, Fig. 7 shows the calculated values of the snow albedo, derived from the airborne observations of the upwelling and downwelling radiative fluxes determined during several experimental days. A general conclusion drawn from Fig. 7 is that the snow albedo values decrease from UV to the NIR wavelengths independently of the snow state and the sky condition. In particular, the blue and aqua (fresh snow) lines depict the albedo snow values that were observed at the Arctic drift station in 1979 (Radionov et al., 1981), the cornflower line that of the Arctic drift station in 1979 again, but under cloudy sky, and the cyan line that of the Arctic drift station in 1979, but for wet snow under cloudy sky.

The direct conclusion is thus that the wet snow is characterised by a $45 \%$ reduction in the albedo spectral profile. The profile of the wet snow albedo was also measured at Ladoga on 28 April 1985 (dark green line in Fig. 7) and on 29 April 1985 (green line in Fig. 7). The brown line in Fig. 7 illustrates the snow albedo measured at Ladoga on the overcast day of 20 April 1985.

A comparison between Figs. 1 and 7 reveals that the spectral dependence of snow albedo behaves similarly to that of water, notably that both albedos decrease from the UV to the NIR wavelengths by $20-50 \%$, despite the fact that their values differ by one order of magnitude (water albedo being lower).

\subsubsection{Snow albedo vs. wavelength in the UV region}

In Sect. 3.3.1 and in particular in Fig. 7 it has been noticed that the profiles observed at Ladoga on 28 April 1985, 

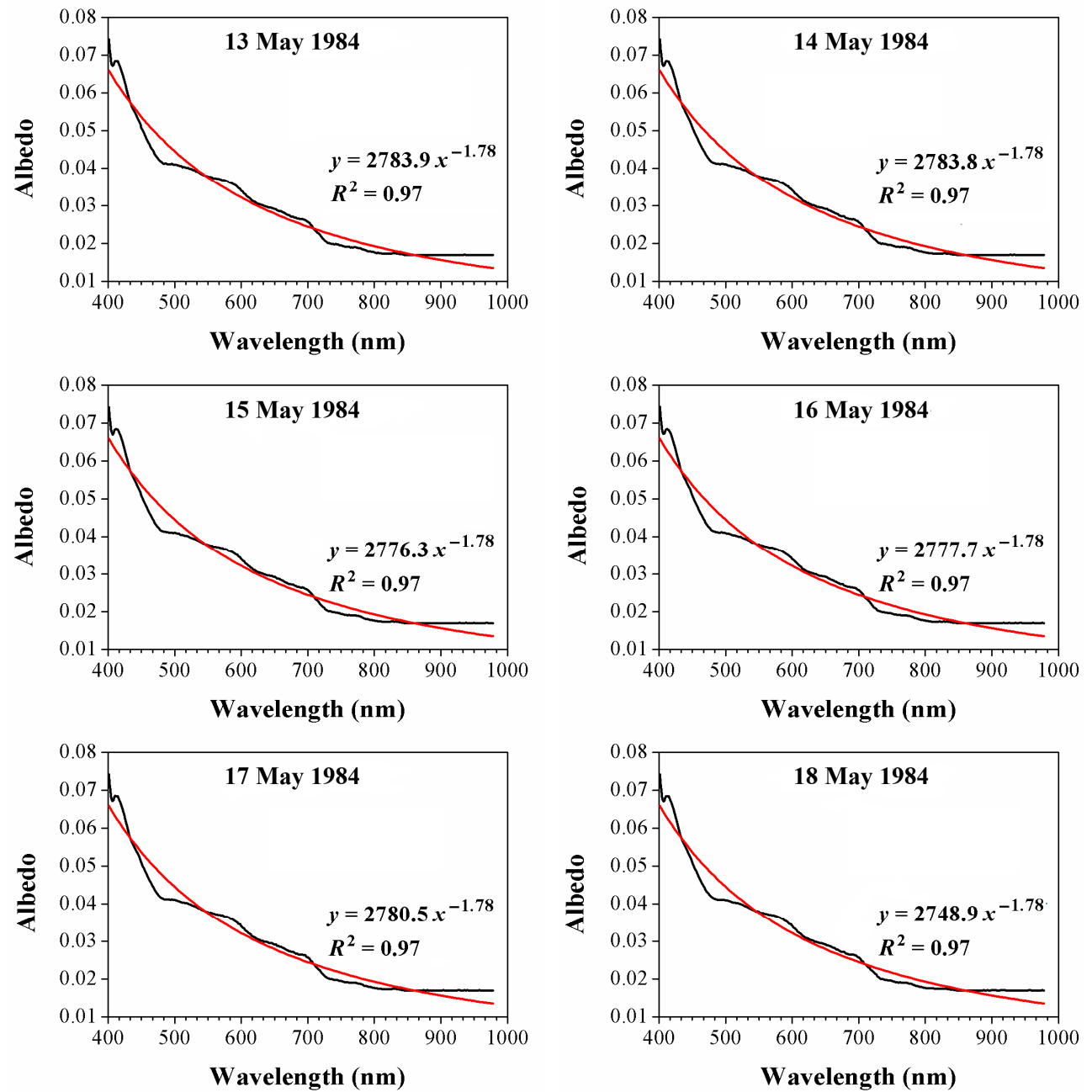

Figure 3. Spectral dependence of water albedo (above Lake Ladoga) in the visible and near-infrared spectra (neglecting UV), as deduced from airborne observations conducted on six consecutive days.

Table 6. Dates and fit equations along with the errors of the coefficients for sand albedo shown in Fig. 6. All given $a, b$, and $c$ values are statistically significant at the $95 \%$ confidence interval.

\begin{tabular}{lcccc}
\hline Dates & $\begin{array}{c}\text { Second-order polynomial } \\
\text { fit equation } \\
\left(y=a x^{2}+b x+c\right)\end{array}$ & Error for $a$ & Error for $b$ & Error for $c$ \\
& $y=-2 \times 10^{-6} x^{2}+0.0027 x-0.7092$ & $3.6 \times 10^{-8}$ & $4.9 \times 10^{-5}$ & 0.0161 \\
\hline 9 Oct 1983 & $y=-1 \times 10^{-6} x^{2}+0.0023 x-0.6243$ & $2.2 \times 10^{-8}$ & $3.0 \times 10^{-5}$ & 0.0099 \\
10 Oct 1983 & $y=-1 \times 10^{-6} x^{2}+0.0022 x-0.581$ & $2.2 \times 10^{-8}$ & $3.0 \times 10^{-5}$ & 0.010 \\
11 Oct 1983 & $y=-2 \times 10^{-6} x^{2}+0.0031 x-0.8362$ & $6.8 \times 10^{-8}$ & $9.4 \times 10^{-5}$ & 0.0308 \\
12 Oct 1983 & $y=-10^{-8}$ & $4.0 \times 10^{-5}$ & 0.0132 \\
13 Oct 1983 & $y=-1 \times 10^{-6} x^{2}+0.0021 x-0.5067$ & $2.9 \times 10^{-8}$ & \\
14 Oct 1983 & $y=-1 \times 10^{-6} x^{2}+0.0025 x-0.6439$ & $3.2 \times 10^{-8}$ & $4.5 \times 10^{-5}$ & 0.0147 \\
16 Oct 1983 & $y=-2 \times 10^{-6} x^{2}+0.0029 x-0.8059$ & $7.6 \times 10^{-8}$ & $1.0 \times 10^{-4}$ & 0.0341 \\
19 Oct 1984 & $y=-2 \times 10^{-6} x^{2}+0.0029 x-0.7338$ & $4.8 \times 10^{-8}$ & $6.6 \times 10^{-5}$ & 0.0218 \\
23 Oct 1984 & $y=-1 \times 10^{-6} x^{2}+0.0023 x-0.5344$ & $3.3 \times 10^{-8}$ & $4.5 \times 10^{-5}$ & 0.0149 \\
24 Oct 1984 & $y=-2 \times 10^{-6} x^{2}+0.0032 x-0.7814$ & $5.4 \times 10^{-8}$ & $7.5 \times 10^{-5}$ & 0.0245 \\
26 Oct 1984 & $y=-2 \times 10^{-6} x^{2}+0.0035 x-0.8911$ & $7.5 \times 10^{-8}$ & $1.0 \times 10^{-4}$ & 0.0341 \\
\hline
\end{tabular}


Table 7. Dates and fit equations along with the errors of the coefficients for snow albedo shown in Fig. 9. All given $a, b$, and $c$ values are statistically significant at the $95 \%$ confidence interval.

\begin{tabular}{lcccc}
\hline Dates & $\begin{array}{c}\text { Second-order polynomial } \\
\text { fit equation } \\
\left(y=a x^{2}+b x+c\right)\end{array}$ & Error for $a$ & Error for $b$ & Error for $c$ \\
& $y=-7 \times 10^{-7} x^{2}+0.0005 x+0.5743$ & $7.8 \times 10^{-8}$ & $1.1 \times 10^{-4}$ & 0.0357 \\
\hline 20 Apr 1985 & $y=-6 \times 10^{-7} x^{2}+0.0003 x+0.6252$ & $5.2 \times 10^{-8}$ & $7.2 \times 10^{-5}$ & 0.0236 \\
28 Apr 1985 & $y=-6.0 .0215$ & $6.5 \times 10^{-8}$ & $9.0 \times 10^{-5}$ & 0.0300 \\
\hline
\end{tabular}

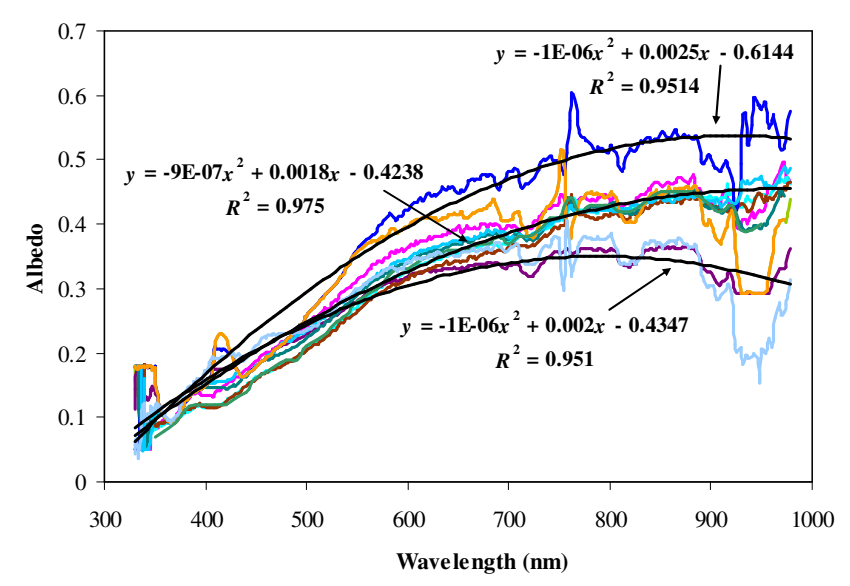

Figure 4. Spectral dependence of the sand albedo. For instance, blue line: measured at the Kara-Kum Desert on 12 October 1983, turquoise line: measured at the Kara-Kum Desert on 13 October 1983, and violet line: measured at the Kara-Kum Desert on 23 October 1984 .

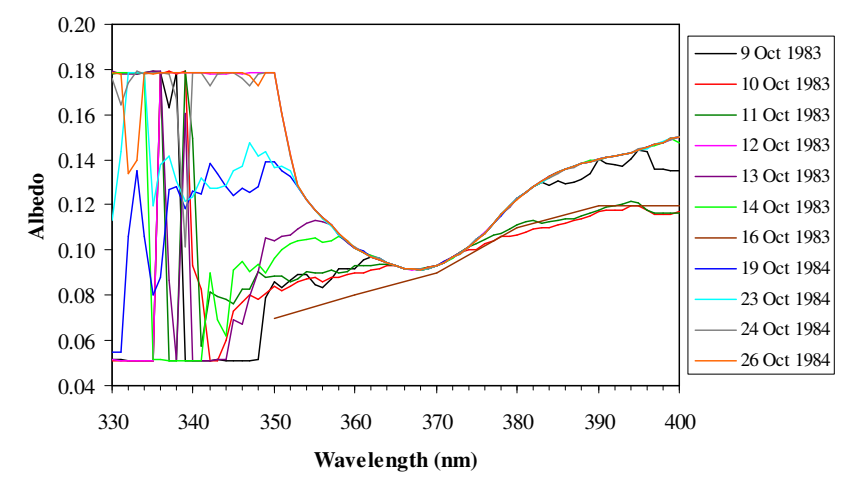

Figure 5. Spectral variability of albedo for the sand surface (above the Kara-Kum Desert) in the UV region measured on 9 October 1983 (black line, 330-400 nm), 10 October 1983 (red line, 330$400 \mathrm{~nm}$ ), 11 October 1983 (green line, 330-400 nm), 12 October 1983 (pink line, 330-400 nm), 13 October 1983 (violet line, 330$400 \mathrm{~nm}$ ), 14 October 1983 (bright green line, 330-400 nm), 16 October 1983 (brown line, $350-400 \mathrm{~nm}$ with a step of $10 \mathrm{~nm}$ ), 19 October 1984 (blue line, 330-400 nm), 23 October 1984 (turquoise line, $330-400 \mathrm{~nm}$ ), 24 October 1984 (grey line, 330-400 nm), and 26 October 1984 (orange line, 330-400 nm).
29 April 1985 and on the cloudy day of 20 April 1985 are characterised by a decrease in snow albedo as a function of wavelength from the UV to the infrared spectrum. However, in the UV spectrum this decrease is not the case. That is why the snow albedo derived from the airborne radiative upward and downward fluxes conducted on the same dates shown in Fig. 7 (20, 28, and 29 April 1985) is plotted in Fig. 8 along with the additional experimental days 26 March 1984 and 14 April 1985.

The message taken from Fig. 8 is that there is no such longterm decrease in snow albedo with wavelength in the UV region. Instead, it may be said that the snow albedo vs. UV wavelength is almost constant, despite the short-term fluctuations, especially in the short wavelengths. Focusing on the brown line (29 April 1985), a very slow increase in albedo towards high wavelengths is noted, which is consistent with the observations made by Feister and Grewe (1995) for the spectral albedo of snow-covered surfaces. It is noteworthy that a characteristic minimum in the snow albedo profile is seen clearly around $365 \mathrm{~nm}$ on 26 March 1984 (black line) and 14 April 1985 (blue line), which was also observed in the sand albedo profiles (Fig. 5).

\subsubsection{Snow albedo vs. wavelength in the visible IR region}

Now, keeping in mind the non-sensitivity of the snow albedo in the UV spectrum shown in Sect. 3.3.2, the snow albedo variability as a function of the visible infrared wavelengths is investigated. Figure 9 shows the variability of the snow albedo values as a function of the visible NIR wavelengths.

It is evident from Fig. 9 (see also Table 7 for errors) that the best fit simulating these graphs satisfactorily is the seconddegree polynomial. It should be stressed that although the simulation in the sand and snow profiles vs. wavelength in the visible NIR spectrum is achieved by the second-degree polynomial, their slopes are opposite. In addition, the results depicted in Fig. 9 (as well as in Fig. 3) do not support the suggestion by Feister and Grewe (1995) that the spectral albedo generally increases with increasing wavelengths for all kinds of surfaces. 

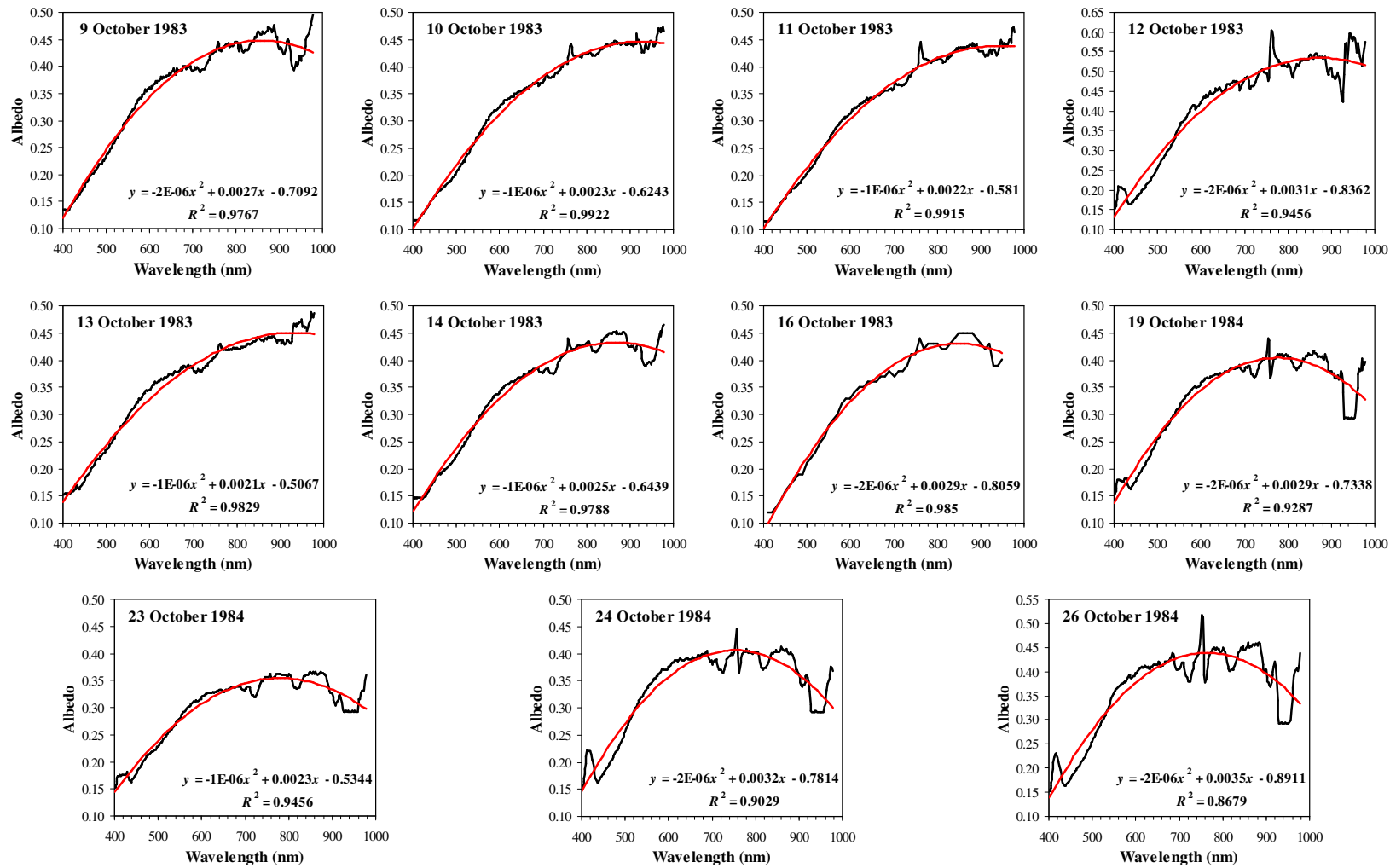

Figure 6. Spectral dependence of albedo for the sand surface (above the Kara-Kum Desert) in the visible and infrared spectra, as deduced from airborne observations conducted on the following 11 days: 9 October 1983 (401-978 nm), 10 October 1983 (401-978 nm), 11 October 1983 (401-978 nm), 12 October 1983 (401-978 nm), 13 October 1983 (401-978 nm), 14 October 1983 (401-978 nm), 16 October 1983 $(410-950 \mathrm{~nm}$ with a step of $10 \mathrm{~nm}), 19$ October $1984(401-978 \mathrm{~nm}), 23$ October 1984 (401-978 nm), 24 October 1984 (401-978 nm), and 26 October 1984 (401-978 nm).

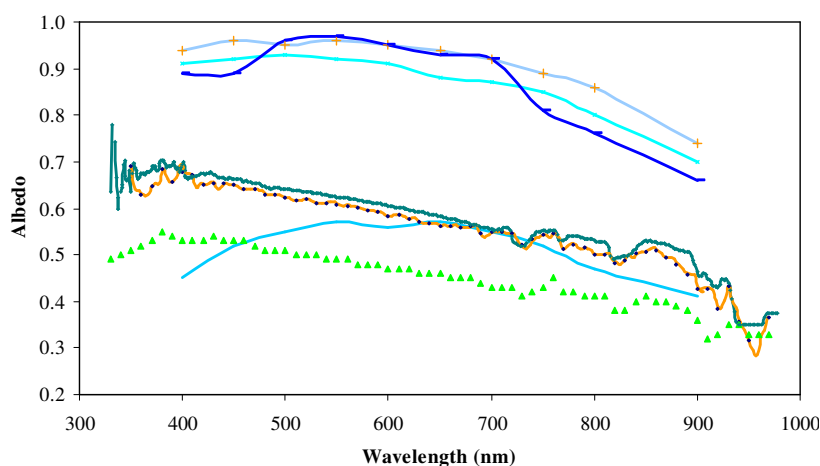

Figure 7. Spectral dependence of the snow albedo under different snow and sky conditions. The blue and aqua (fresh snow) lines: at the Arctic drift station in 1979. The cornflower line: at the Arctic drift station in 1979 under cloudy sky. The cyan line: at the Arctic drift station in 1979 for wet snow under cloudy sky. The dark green line: at Ladoga on 28 April 1985 (wet snow). The green line: at Ladoga on 29 April 1985 (wet snow). The brown line: at Ladoga on the cloudy day of 20 April 1985 (wet snow).

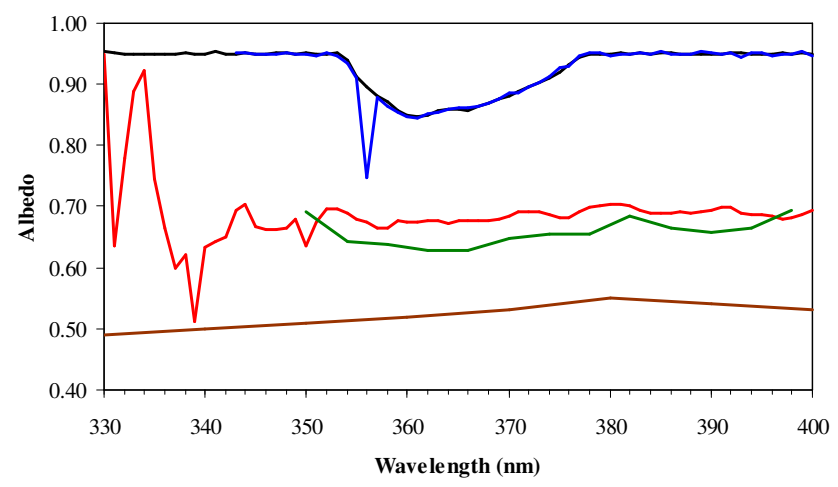

Figure 8. Spectral dependence of the snow albedo (Lake Ladoga) under different snow and sky conditions in the UV region: 26 March 1984 (black line, fresh snow, 330-400 nm), 14 April 1985 (blue line, wet snow, 343-400 nm), 20 April 1985 (green line, cloudy, wet snow, 350-398 nm with a step of $4 \mathrm{~nm}$ ), 28 April 1985 (red line, wet snow, 330-400 nm), and 29 April 1985 (brown line, wet snow, $330-400 \mathrm{~nm}$, with a step of $10 \mathrm{~nm}$ ). 

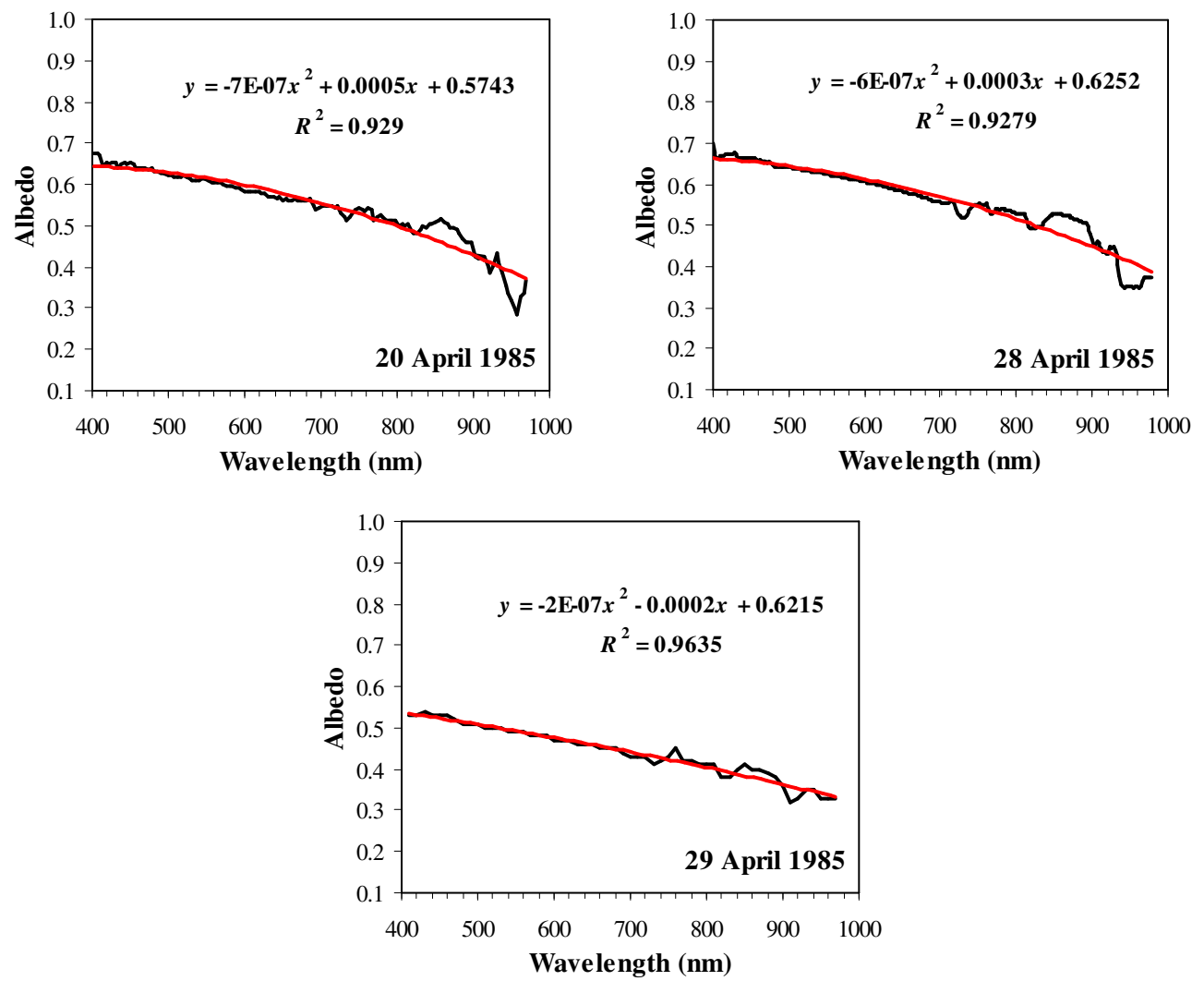

Figure 9. Spectral dependence of snow albedo (Lake Ladoga) in the visible and infrared spectra, as deduced from airborne observations conducted on 20 April 1985 (cloudy, wet snow, 402-968 nm, with a step of $4 \mathrm{~nm}$ ), 28 April 1985 (wet snow, 401-978 nm), and 29 April 1985 (wet snow, 410-970 $\mathrm{nm}$, with a step of $10 \mathrm{~nm}$ ).

\subsection{Utility of the spectral albedo functions for remote sensing applications}

As mentioned in the Introduction, surface albedo plays a crucial role in remote sensing applications. For instance, it is a key parameter in satellite climate change monitoring, since it controls the radiation energy budget. However, the surface albedo constitutes a significant source of radiative uncertainties in the current general circulation models that require an absolute accuracy of 0.02-0.05 units for snow albedo, a target that is not feasible, as yet, by the albedo retrieved from remote sensing data.

The spectral functions of the near-ground albedo proposed in this study provide a suitable tool for overcoming this difficulty, since the mean absolute accuracy for snow albedo in NIR ( \pm 0.005 in Fig. 9) is almost one order of magnitude lower than the ones requested by the models.

Another remote sensing application is the monitoring of the Earth's radiation budget, which is traditionally calculated as the absorbed shortwave radiation minus the outgoing longwave radiation, utilising the surface albedo as the critical parameter. This has been discerned from the Earth Radiation Budget Experiment (ERBE), where it is obvious that small albedo deviations correspond to large amounts of energy, thus influencing regional and global climate. As mentioned in the Introduction, albedo is dependent on the bidirectional reflectance distribution function, and the assumption that the surface reflects isotropically (i.e. equally at all angles, thus referred to as "diffuse albedo" or "hemispherical albedo") can lead to large errors when surfaces appear with high anisotropy. This is very important in the efforts to retrieve surface albedo measurements from satellite remote sensing data. As an example, a strong cooling effect on the global climate may be concluded from the assumption of a high snow albedo, i.e. 0.8 . Figures 8 and 9 however show that the spectral snow albedo varies from 0.95 to 0.3 and therefore the afore-mentioned claim is not valid. Similar conclusions can be drawn for the cases of the water and sand surfaces that were discussed in Sects. 3.1 and 3.2.

\section{Conclusions}

Several uncertainties exist in the retrievals of various atmospheric constituents and parameters deduced by spaceborne instrumentation, which are closely associated with the accuracy and precision of the surface albedo. To evaluate and 
improve the quality of satellite retrievals, careful intercomparisons with in situ measurements of surface albedo are crucial in order to develop the accuracy, especially for inaccessible areas where in situ measurements may be expensive and dangerous. In this context, the above-mentioned discussion leads briefly to the following conclusions:

1. The near-ground albedo depends strongly on the wavelength spectrum and the ground surface, but the current belief that the spectral albedo generally increases with increasing wavelengths for all kinds of surfaces is not valid (e.g. see the case of snow).

2. In the case of water surfaces the albedo in the UV region is governed by rather low wavelength dependence. In the visible and near-infrared spectra the water albedo obeys a constant power-law relationship with wavelength.

3. In the case of sand surface, the sand albedo is a quadratic function of wavelength, which becomes more accurate if the UV wavelengths are neglected.

4. The spectral dependence of snow albedo behaves similarly to that of water, i.e. both decrease from the UV to the near-infrared wavelengths by $20-50 \%$, despite the fact that their values differ by one order of magnitude (water albedo being lower). The snow albedo vs. UV wavelength is almost constant, while in the visible nearinfrared spectrum the best fit is achieved by a seconddegree polynomial, with an opposite slope to that of sand.

The consideration of these conclusions in the investigation of the remotely sensed atmospheric constituents and parameters may increase their observational accuracy and reduce the large uncertainties in the radiative forcing, which depend on the surface albedo inaccuracies (Myhre and Myhre, 2003). In addition, the spectral albedo functions derived above provide the albedo accuracies required for climate change applications. Finally, the spectral albedo functions of different surfaces found above may contribute to the optimisation of future remote sensing sensors for various applications. Furthermore, although the surface albedo variability in time and space can be retrieved with the use of remote sensing products available nowadays from different satellite platforms (e.g. Terra and Aqua MODIS), careful intercomparisons with in situ measurements of surface albedo are crucial to evaluating and improving the quality of remote sensing products (Cescatti et al., 2012).
Acknowledgements. The authors express their profound gratitude to Anatoly Kovalenko, Natalya Maltseva, Victor Ovcharenko, Lyudmila Poberovskaya, Igor Tovstenko and Vladimir Mikhailov, who have taken part in the preparation of the instruments, the accomplishment of the observations, and the data processing. Unfortunately, our colleagues Pavel Baldin, Vladimir Grishechkin, Alexei Nikiforov and Oleg Vasilyev have passed away prematurely. This study was partly funded by the Greek General Secretariat for Research and Technology (GSRT) through project 12CHN350.

Edited by: A. Hofzumahaus

\section{References}

Alexandris, D., Varotsos, C., Kondratyev, K. Y., and Chronopoulos, G.: On the altitude dependence of solar effective UV, Phys. Chem. Earth, 24, 515-517, 1999.

Boucher, O.: On aerosol direct shortwave forcing and the HenyeyGreenstein phase function, J. Atmos. Sci., 55, 128-134, 1998.

Brandt, R. E., Warren, S. G., and Clarke, A. D.: A controlled snowmaking experiment testing the relation between black carbon content and reduction of snow albedo, J. Geophys. Res., 116, D08109, doi:10.1029/2010JD015330, 2011.

Cescatti, A., Marcolla, B., Vannan, S. K. S., Pan, J. Y., Román, M. O., Yang, X., Ciais, P., Cook, R. B., Law, B. E., Matteucci, G., Migliavacca, M., Moors, E., Richardson, A. D., Seufert, G. E., and Schaaf, C. B.: Intercomparison of MODIS albedo retrievals and in situ measurements across the global FLUXNET network, Remote Sens. Environ., 121, 323-334, 2012.

Chattopadhyay, S. and Chattopadhyay, G.: Univariate modelling of summer-monsoon rainfall time series: Comparison between ARIMA and ARNN, C. Roy. Geosci., 342, 100-107, 2010.

Cracknell, A. P. and Varotsos, C. A.: Ozone depletion over Scotland as derived from Nimbus-7 TOMS measurements, Int. J. Remote Sens., 15, 2659-2668, 1994.

Cracknell, A. P. and Varotsos, C. A.: The present status of the total ozone depletion over Greece and Scotland - A comparison between Mediterranean and more northerly latitudes, Int. J. Remote Sens., 16, 1751-1763, 1995.

Cracknell, A. P. and Varotsos, C. A.: The IPCC Fourth Assessment Report and the fiftieth anniversary of Sputnik, Environ. Sci. Pollut. R., 14, 384-387, 2007a.

Cracknell, A. P. and Varotsos, C. A.: The Antarctic 2006 ozone hole, Int. J. Remote Sens., 28, 1-2, 2007b.

Cracknell, A. P. and Varotsos, C. A.: Fifty years after the first artificial satellite: from Sputnik 1 to ENVISAT, Int. J. Remote Sens. 28, 2071-2072, 2007c.

de la Fuente, D., Vega, J. M., Viejo, F., Diaz, I., and Morcillo, M.: City scale assessment model for air pollution effects on the cultural heritage, Atmos. Environ., 45, 1242-1250, 2011.

Doherty, S. J., Warren, S. G., Grenfell, T. C., Clarke, A. D., and Brandt, R. E.: Light-absorbing impurities in Arctic snow, Atmos. Chem. Phys., 10, 11647-11680, doi:10.5194/acp-1011647-2010, 2010.

Efstathiou, M. N. and Varotsos, C.: On the altitude dependence of the temperature scaling behavior at the global troposphere, Int. J. Remote Sens., 31, 343-349, 2010. 
Efstathiou, M. N. and Varotsos, C. A.: On the 11 year solar cycle signature in global total ozone dynamics, Meteorol. Appl., 20, 72-79, 2013.

Efstathiou, M. N., Varotsos, C. A., Singh, R. P., Cracknell, A. P., and Tzanis, C.: On the longitude dependence of total ozone trends over middle-latitudes, Int. J. Remote Sens., 24, 13611367, 2003

Feister, U. and Grewe, R.: Spectral albedo measurements in the UV and visible region over different types of surfaces, Photochem. Photobiol., 62, 736-744, 1995.

Feretis, E., Theodorakopoulos, P., Varotsos, C., Efstathiou, M., Tzanis, C., Xirou, T., Alexandridou, N., and Aggelou, M.: On the plausible association between environmental conditions and human eye damage, Environ. Sci. Pollut. R., 9, 163-165, 2002.

Flanner, M. G., Zender, C. S., Randerson, J. T., and Rasch, P. J.: Present-day climate forcing and response from black carbon in snow, J. Geophys. Res., 112, D11202, doi:10.1029/2006JD008003, 2007.

Gallet, J. C., Domine, F., Zender, C. S., and Picard, G.: Measurement of the specific surface area of snow using infrared reflectance in an integrating sphere at 1310 and $1550 \mathrm{~nm}$, The Cryosphere, 3, 167-182, doi:10.5194/tc-3-167-2009, 2009.

Gatebe, C. K., King, M. D., Platnick, S., Arnold, G. T., Vermote, E. F., and Schmid, B.: Airborne spectral measurements of surface-atmosphere anisotropy for several surfaces and ecosystems over southern Africa, J. Geophys. Res., 108, 8489, doi:10.1029/2002JD002397, 2003.

Gatebe, C. K., King, M. D., Lyapustin, A. I., Arnold, G. T., and Redemann, J.: Airborne spectral measurements of ocean directional reflectance, J. Atmos. Sci., 62, 1072-1092, doi:10.1175/JAS3386.1, 2005.

Genya, M. J., Melnikova, I., and Gatebe, C.: Comparing Products of processing airborne NASA and Russian Cloud Data, paper presented at 34th International Symposium on Remote Sensing of Environment. The GEOSS Era: Towards Operational Environmental Monitoring, Sydney, 10-15 April, 2011.

Hadley, O. L. and Kirchstetter, T. W.: Black-carbon reduction of snow albedo, Nat. Clim. Change, 2, 437-440, 2012

Haltrin, V. I., McBride III, W. E., and Arnone, R. A.: Spectral approach to calculate specular reflection of light from wavy water surface, paper presented at D. S. Rozhdestvensky Optical Society: International Conference Current Problems in Optics of Natural Waters (ONW'2001), St. Petersburg, Russia, 133-138, 2001.

Hansen, J. and Nazarenko, L.: Soot climate forcing via snow and ice albedos, P. Natl. Acad. Sci. USA, 101, 423-428, 2004.

Katsambas, A., Varotsos, C. A., Veziryianni, G., and Antoniou, C.: Surface solar ultraviolet radiation: A theoretical approach of the SUVR reaching the ground in Athens, Greece, Environ. Sci. Pollut. R., 4, 69-73, 1997.

King, M. D.: Determination of the scaled optical thickness of clouds from reflected solar radiation measurements, J. Atmos. Sci., 44, 1734-1751, 1987.

King, M. D., Radke, L. F., and Hobbs, P. V.: Determination of the spectral absorption of solar radiation by marine stratocumulus clouds from airborne measurements within clouds, J. Atmos. Sci., 47, 894-907, 1990.

King, M. D., Menzel, W. P., Grant, P. S., Myers, J. S., Arnold, G. T., Platnick, S. E., Gumley, L. E., Tsay, S. C., Moeller, C. C.,
Fitzgerald, M., Brown, K. S., and Osterwisch, F. G.: Airborne scanning spectrometer for remote sensing of cloud, aerosol, water vapor and surface properties, J. Atmos. Ocean. Tech., 13, 777-794, 1996.

Kokhanovsky, A.: Variability of the phase function of atmospheric aerosols at large scattering angles, J. Atmos. Sci., 55, 314-320, 1998.

Kondratyev, K. Y. and Varotsos C.: Atmospheric greenhouse effect in the context of global climate-change, Nuovo Cim. Soc. Ital. Fisica C - Geophys. Space Phys., 18, 123-151, 1995a.

Kondratyev, K. Y. and Varotsos, C. A.: Volcanic eruptions and global ozone dynamics, Int. J. Remote Sens., 16, 1887-1895, $1995 b$.

Kondratyev, K. Y. and Varotsos, C. A.: Global total ozone dynamics - Impact on surface solar ultraviolet radiation variability and ecosystems, Environ. Sci. Pollut. R., 3, 205-209, 1996a.

Kondratyev, K. Y. and Varotsos, C. A.: Global total ozone dynamics - Impact on surface solar ultraviolet radiation variability and ecosystems - 1: Global ozone dynamics and environmental safety, Environ. Sci. Pollut. R., 3, 153-157, 1996 b.

Kondratyev, K. Y., Pokrovsky, O. M., and Varotsos, C. A.: Atmospheric ozone trends and other factors of surface ultraviolet radiation variability, Environ. Conserv., 22, 259-261, 1995.

Kostopoulos, D., Varotsos, P., and Mourikis, S.: The conductivity of crystalline NaI, Can. J. Phys., 53, 1318-1320, 1975.

Lyapustin, A., Tedesco, M., Wang, Y. J., Aoki, T., Hori, M., and Kokhanovsky, A.: Retrieval of snow grain size over Greenland from MODIS, Remote Sens. Environ., 113, 1976-1987, 2009.

McArthur, L. J. B.: Baseline Surface Radiation Network (BSRN) Operations Manual V2.1, WCRP 121, WMO/TD-No. 1274, 2005.

Melnikova, I. N.: Retrieval of the transmitted UV irradiance from reflected data observed, Int. J. Remote Sens., 26, 3539-3544, 2005.

Melnikova, I. N. and Mikhaylov, V. V.: Spectral scattering and absorption coefficients in Strati derived from aircraft measurements, J. Atmos. Sci., 51, 925-931, 1994.

Melnikova, I. N. and Vasilyev, A. V.: Short-Wave Solar Radiation in the Earth's Atmosphere: Calculation, Observation, Interpretation, Berlin/Heidelberg: Springer/GmbH \& Co. KG, p. 310, 2004.

Melnikova, I. N., Dlugach, Zh. M., Nakajima, T., and Kawamoto, K.: Calculation of the reflected function of an optically thick scattering layer for a Henyey-Greenstein phase function, Appl. Optics, 39, 4195-4204, 2000.

Monks, P. S., Rickard, A. R., Hall, S. L., and Richards, N. A. D.: Attenuation of spectral actinic flux and photolysis frequencies at the surface through homogenous cloud fields, J. Geophys. Res., 109, D17206, doi:10.1029/2003JD004076, 2004.

Myhre, G. and Myhre, A.: Uncertainties in radiative forcing due to surface albedo changes caused by land-use changes, J. Climate, 16, 1511-1524, 2003.

Pegau, W. S. and Paulson, C. A.: The albedo of Arctic leads in summer, Ann. Glaciol., 33, 221-224, 2001.

Radionov, V. F., Sakunov, G. G., and Grishechkin, V. S.: Spectral albedo of snow surface from measurements at drifting station SP-22, in "First global experiment FGGE, 2. Polar aerosols, extended cloudiness and radiation", 89-91, Leningrad: Gidrometeoizdat (in Russian), 1981. 
Román, M. O., Gatebe, C. K., Schaaf, C. B., Poudyal, R., Wang, Z. S., and King, M. D.: Variability in surface BRDF at different spatial scales $(30 \mathrm{~m}-500 \mathrm{~m})$ over a mixed agricultural landscape as retrieved from airborne and satellite spectral measurements, Remote Sens. Environ., 115, 2184-2203, 2011.

Schaepman-Strub, G., Schaepman, M. E., Painter, T. H., Dangel, S., and Martonchik, J. V.: Reflectance quantities in optical remote sensing - definitions and case studies, Remote Sens. Environ., 103, 27-42, 2006.

Seidel, F. C., and Popp, C.: Critical surface albedo and its implications to aerosol remote sensing, Atmos. Meas. Tech., 5, 16531665,2012 , http://www.atmos-meas-tech.net/5/1653/2012/.

Teillet, P. M., Fedosejevs, G., Ahern, F. J., and Gauthier, R. P.: Sensitivity of surface reflectance retrieval to uncertainties in aerosol optical properties, Appl. Optics, 33, 3933-3940, 1994.

Tzanis, C., Varotsos, C., and Viras, L.: Impacts of the solar eclipse of 29 March 2006 on the surface ozone concentration, the solar ultraviolet radiation and the meteorological parameters at Athens, Greece, Atmos. Chem. Phys., 8, 425-430, doi:10.5194/acp-8-425-2008, 2008.

Varotsos, C.: The southern hemisphere ozone hole split in 2002, Environ. Sci. Pollut. R., 9, 375-376, 2002.

Varotsos, C.: Power-law correlations in column ozone over Antarctica, Int. J. Remote Sens., 26, 3333-3342, 2005a.

Varotsos, C.: Airborne measurements of aerosol, ozone, and solar ultraviolet irradiance in the troposphere, J. Geophys. Res., 110, D09202, doi:10.1029/2004JD005397, 2005b.

Varotsos, C., Ondov, J., Tzanis, C., Ozturk, F., Nelson, M., Ke, H., and Christodoulakis, J.: An observational study of the atmospheric ultra-fine particle dynamics, Atmos. Environ., 59, 312319, 2012a.
Varotsos, C. A., Chronopoulos, G. J., Katsikis, S., and Sakellariou, N. K.: Further evidence of the role of air-pollution on solar ultraviolet radiation reaching the ground, Int. J. Remote Sens., 16, 1883-1886, 1995.

Varotsos, C. A., Milinevsky, G., Grytsai, A., Efstathiou, M., and Tzanis, C.: Scaling effect in planetary waves over Antarctica, Int. J. Remote Sens., 29, 2697-2704, 2008.

Varotsos, C. A., Cracknell, A. P., and Tzanis, C.: The exceptional ozone depletion over the Arctic in January-March 2011, Remote Sens. Lett., 3, 343-352, 2012b.

Varotsos, P.: Determination of the dielectric constant of alkali halide mixed crystals, Phys. Status Solidi B, 100, K133-138, 1980.

Varotsos, P. and Miliotis, D.: New aspects on the dielectric properties of the alkali halides with divalent impurities, J. Phys. Chem. Solids, 35, 927-930, 1974.

Webb, A. R., Stromberg, I. M., Li, H., and Bartlett, L. M.: Airborne spectral measurements of surface reflectivity at ultraviolet and visible wavelengths, J. Geophys. Res., 105, 4945-4948, doi:10.1029/1999JD900813, 2000.

Wendisch, M., Pilewskie, P., Jäkel, E., Schmidt, S., Pommier, J., Howard, S., Jonsson, H. H., Guan, H., Schröder, M., and Mayer, B.: Airborne measurements of areal spectral surface albedo over different sea and land surfaces, J. Geophys. Res., 109, D08203, doi:10.1029/2003JD004392, 2004.

Xue, Y., Ai, J. W., Wan, W., Guo, H. D., Li, Y. J., Wang, Y., Guang, J., Mei, L. L., and Xu, H.: Grid-enabled high-performance quantitative aerosol retrieval from remotely sensed data, Comput. Geosci.-UK, 37, 202-206, 2011. 